when $t=\infty$, these equations can be integrated to give

$$
-\ln \left(l-\frac{x}{x_{\infty}}\right)=R\left(\frac{a+b}{a b}\right) t .
$$

Thus the shape of the $x, t$ - curve is given exactly by simple theory, and is independent of the form of $R$; whether the reaction is uni-, bi-, or termolecular, or something more complicated, the $x, t$ - curve is that for a reversible unimolecular reaction.

The reason for this particularly simple result is, of course, that the composition of the reacting mixture remains chemically unchanged throughout the reaction, so that we get $k \cdot \frac{x}{a} \cdot f(a) \varphi(b)$ insteadof $k \cdot f\left(\frac{x}{a}\right) \varphi(b)$ for the rate of the forward reaction, and a similar expression for the rate of the backward reaction. By changing $a$ and $b$ we can, of course, determine $f(a)$ and $\varphi(b)$, that is, determine the order of the reaction.

H. A. C. McKay.

(Beit Scientific Research Fellow.) Imperial College of Science and Technology, London, S.W.7.

Nov. 12

\section{Manifold Effects of Male and Female Sex Hormones in both Sexes}

IN our previous experiments ${ }^{1}$ the hormones were usually injected into gonadectomized rats for a period of 2I-23 days. This comparatively short treatment produced definite effects on the nonsexual organs (except spleen) of males, but the effects were less evident or absent in most of these organs in females.

In the present experiments, 91 castrated and 88 ovariectomized rats have been injected for a period of $2 \frac{1}{2}$ to 4 months with the following hormones and doses (per week): androsterone $7.5 \mathrm{mgm}$.; trans. dehydroandrosterone $7.5 \mathrm{mgm}$.; testosterone propionate $0.75-7.5 \mathrm{mgm}$. ; and (in males only) testosterone $0 \cdot 75-7.5 \mathrm{mgm}$., alone or simultaneously with œstradiol dipropionate, 0.018-0.200 mgm., our usual experimental technique being used ${ }^{1}$.

The effects obtained on the organs investigated were very similar in males and females, varying as a rule only in degree. The accompanying table containing, for the sake of economy of space, the average weights of some organs only, gives examples of the changes observed in females.

\begin{tabular}{|c|c|c|c|c|c|}
\hline \multicolumn{2}{|c|}{ Hormone injected } & \multicolumn{4}{|c|}{ Actual weights of organs } \\
\hline $\begin{array}{l}\text { Male hormone } \\
\text { (mgm. per week) }\end{array}$ & $\begin{array}{c}\text { Estradiol } \\
\text { dipro- } \\
\text { pionate } \\
\text { (mgm.) } \\
\text { per wk. }\end{array}$ & $\begin{array}{l}\text { Hypo- } \\
\text { physis } \\
\text { (mgm.) }\end{array}$ & $\begin{array}{l}\text { Liver } \\
\text { (gm.) }\end{array}$ & $\begin{array}{c}\text { Heart } \\
\text { (mgm.) }\end{array}$ & $\begin{array}{l}\text { Gain } \\
\text { in } \\
\text { body } \\
\text { wt. } \\
\text { (gm.) }\end{array}$ \\
\hline None (control rats) & none & $11 \cdot 9$ & $8 \cdot 31$ & 737 & 165 \\
\hline None $\quad \ldots \quad \ldots$ & 0.090 & $98 \cdot 0$ & $7 \cdot 61$ & 623 & 73 \\
\hline None $\quad .$. & $0 \cdot 200$ & $132 \cdot 2$ & $6 \cdot 77$ & 596 & 13 \\
\hline Androsterone, $7 \cdot 5$ & none & $10 \cdot 8$ & $11 \cdot 39$ & 928 & 199 \\
\hline Androsterone, $7 \cdot 5$ & $0 \cdot 090$ & $48 \cdot 0$ & $8 \cdot 96$ & 723 & 112 \\
\hline Testosterone prop., $2 \cdot 25$ & none & $10 \cdot 9$ & $10 \cdot 42$ & 935 & 139 \\
\hline Testosterone prop., $2 \cdot 25$ & $0 \cdot 200$ & $60 \cdot 2$ & $7 \cdot 91$ & 621 & 64 \\
\hline
\end{tabular}

Some important conclusions are obvious from the data given in this table and from the other results (not given here) obtained with females and males.

(1) While ostrogens produce stunted growth and decreased fat deposition, with the male hormones this depressing effect is absent or (with large doses of testosterone propionate) slight.
(2) Moreover, this depressing effect of œstrogens is to some extent neutralized by the simultanoous injections of male hormones (except dehydroandrosterone), thus indicating some antagonistic relation between ostrogens and male hormones (see table).

(3) Both male and female hormones accelerate the physiological involution of the thymus, having a co-operative effect on this organ, whon injected simultaneously.

(4) The male hormones have a definite effect on adrenals in males, causing the hypertrophied 'castration' glands to return to or towards normal. The histological changes which occur have been discussed elsewhere (Hall and Korenchevsky ${ }^{2}$ ). Simultaneous injections with œstrogens in most cases prevent this restorative effect on size and weight of adrenals. In females, similar results have been obtained with androsterone, but the effects of the other hormones and of ovariectomy were indefinite.

(5) While male hormones do not produce any considerable change in weight of the hypophysis, certain doses of œstrogens cause a tumour-like hyperplasia of the gland (see table). When injected simultaneously, male hormones neutralize to a considerable extent (in one male rat almost to normal$14 \mathrm{mgm}$.) this hyperplastic effect of œestrogens both in males and (see table) in females. This is another important case of antagonistic relations between male and female hormones.

(6) Slight hypertrophy of liver, kidneys, heart and spleen in gonadectomized animals is produced by male hormones, while œstrogens cause either a decrease in their actual weight or no change (kidneys), This effect of œstrogens is in some organs partly dependent on the body weight, which relation, suggesting a possible stimulating effect on the kidneys, will be discussed elsewhere. When injected simultaneously the effect of male hormones on the actual weights of these organs is antagonistic to, and to some extent neutralizes, that of cestrogens in both sexes (see table).

The data presented (1)confirm adefinition, previously given ${ }^{3}$, of gonadal hormones as not merely sex hormones, but as hormones also possessing manifold important effects on non-sexual organs ; (2) show the co-operative and antagonistic interrelations between male and female hormones, supplementing similar results previously obtained ${ }^{1}$ on sexual organs.

\author{
Lister Institute of \\ Preventive Medicine, \\ London. \\ Oct. 31 \\ ${ }^{1}$ See references: Korenchevsky, V., Brit. Med: J., ii, 896 (1937). \\ ${ }^{2}$ Hall, K., and Korenchevsky, V., J. Physiol., 91, 365 (1938). \\ ${ }^{3}$ Korenchevsky, V., and Dennison, M., J. Path. and Bact., 38, 231
}

V. KORENCHEVSKY. (1934).

\section{Antarctica and Glacial Ages}

In Nature of September 17 there is an interesting discussion between Rev. W. S. Fleming and Prof. E. W. MacBride in regard to the Gondwana flora and glaciation in Antarctica in Permo-carboniferous times which requires some comment. Referring to the Permo-carboniferous ice age, Prof. MacBride suggests that a vast Gondwana continent in temperate parts of the southern hemisphere drifted south across the south pole, Australia and Antarctica, which lay at its north edge, being left behind in temperate 